\title{
Index of Independence
}

\author{
Ilija Barukčić ${ }^{1}$ \\ ${ }^{1}$ Internist, Horandstrasse, DE-26441 Jever, Germany \\ Correspondence: Ilija Barukčić, Horandstrasse, DE-26441 Jever, Germany. Tel: 49-4466-333. E-mail: Barukcic@ \\ t-online.de
}

Received: August 6, 2019; Accepted September 30, 2019; Published: October 7, 2019

\begin{abstract}
Objective. Under certain circumstances, the results of multiple investigations - particularly, rigorously-designed trials, can be summarized by systematic reviews and meta-analyses. However, the results of properly conducted meta-analyses can but need not be stronger than single investigations, if (publication) bias is not considered to a necessary extent.
\end{abstract}

Methods. In assessing the significance of publication bias due to study design simple to handle statistical measures for quantifying publication bias are developed and discussed which can be used as a characteristic of a metaanalysis. In addition, these measures may permit comparisons of publication biases between different metaanalyses.

Results. Various properties and the performance of the new measures of publication bias are studied and illustrated using simulations and clearly described thought experiments. As a result, individual studies can be reviewed with a higher degree of certainty.

Conclusions. Publication bias due to study design is a serious problem in scientific research, which can affect the validity and generalization of conclusions. The index of unfairness and the index of independence are of use to quantify publication bias and to improve the quality of systematic reviews and meta-analyses.

Keywords: study design, study type, measuring technique, publication bias

\section{Introduction}

Objective reality is determined by various events too while some of them occur haphazardly, unpredictably, or by chance. In point of fact, our understanding of both chance and randomness, as we ordinarily think of it and its close connection to probability theory open up the possibility to handle both by specific methods in the light of empirical facts. However, relating facts and hypotheses of a particular kind or extrapolating from a possible data set to predictions and general facts is not free of errors (the problem of induction). The data as recordings of events or of observations, called the sample, the sample data and published by a scientific study are more or less only a set of measurements of individuals from a population. The sample data actually obtained by a study or an experiment may agree perfectly with the population but the same need not. The quality of sample data has a fundamental impact on the validity of the inferences drawn and how believable a hypothesis is, whether it is justified to rely on the hypothesis in our decisions or not. Various types of study designs in research activity should ensure the most rigorous visibility and discoverability of causal mechanisms too. Thus far, before any statistical analyses of a data set is performed, it is appropriate to provide some evidence whether the data set used is of use at all. With these concerns firmly in mind while adopting a bird's-eye view, the problem of study design with its relation to causal and conditional analysis will be covered by this article.

\section{Material and Methods}

In one way or another, testing hypotheses and theories about the natural world is not completely free of errors. Still, when all goes well, systematic observation and experimentation should assure that different scientists at different times and places are able to generate to some extent the same scientific knowledge.

\subsection{Definitions}

Definition 2.1.1 (The sample space)

Let the sample space denote $a$ set or a collection of all different but possible outcomes of an experiment at a certain Bernoulli trial $t$ or point in space time $t$. Each possible single outcome $\mathrm{x}_{\mathrm{t}}$ of the experiment is said to be a member of the sample space, or to belong to the space $S(X)$. A single outcome $x_{t}$ of an experiment $S(X)$ is a member of 
$\mathrm{S}(\mathrm{X})$ and denoted symbolically by the relation $\mathrm{x}_{\mathrm{t}} \in \mathrm{S}(\mathrm{X})$. A set $\mathrm{Y}$ is contained in another set $\mathrm{X}$ if every element of the set $\mathrm{Y}$ also belongs to the set $\mathrm{X}$. This relation is expressed symbolically by the expression $\mathrm{Y} \subset \mathrm{X}$, which is the set-theoretic expression for saying that $\mathrm{Y}$ is a subset of $\mathrm{X}$. A subset of $\mathrm{X}$ that contains no elements is called an empty set, or null set, and it is denoted by the symbol $\emptyset$. In a given experiment, a number $\mathrm{p}\left(\mathrm{x}_{\mathrm{t}}\right)$ is assigned to each event $x_{t}$ in the sample space $S$ which indicates the probability that $x_{t}$ will occur. If the event $x_{t}$ is certain to occur, then the probability of that event is $\mathrm{p}\left(\mathrm{x}_{\mathrm{t}}\right)=1$.

Definition 2.1.2 (The $2 \times 2$ Table)

A two by two table (also called a contingency table, a notion first used by Karl Pearson (Pearson, 1904) in 1904) is a useful tool for examining relationships between Bernoulli (i. e. Binomial) distributed random variables. Consider the case of a Bernoulli distributed random variable $A_{t}$ occurring/existing et cetera with the probability $p\left(A_{t}\right)$ at the Bernoulli trial or (period of) time t. Furthermore, consider the case of another Bernoulli distributed random variable $B_{t}$ occurring/existing et cetera with the probability $p\left(B_{t}\right)$ at the same Bernoulli trial or (period of) time t. Furthermore, let $p\left(a_{t}\right)=p\left(A_{t} \cap B_{t}\right)$ denote the joint probability distribution of $A_{t}$ and $B_{t}$ at the same Bernoulli trial or (period of) time t. The following table (Table 1) may show the relationships in more details.

Table 1 . The probabitlities of a contingency table



In this context, it is per definitionem

$$
\begin{aligned}
& p\left(A_{t}\right) \equiv p\left(a_{t}\right)+p\left(b_{t}\right) \quad=\quad 1-p\left(\underline{A}_{t}\right) \\
& p\left(B_{t}\right) \equiv p\left(a_{t}\right)+p\left(c_{t}\right) \quad=\quad 1-p\left(\underline{B}_{t}\right) \\
& p\left(a_{t}\right) \equiv \quad p\left(A_{t} \cap B_{t}\right) \\
& +1 \quad \equiv \quad p\left(a_{t}\right)+p\left(b_{t}\right) \\
& +1 \quad \equiv \\
& p\left(A_{t}\right)+p\left(\underline{A}_{t}\right) \\
& p\left(A_{t}\right) \quad= \\
& =1-p\left(b_{t}\right)-p\left(c_{t}\right)-p\left(d_{t}\right) \\
& p\left(B_{t}\right)+p\left(\Lambda_{t}\right) \equiv \\
& p\left(\underline{A}_{t}\right)=1-\left(1-p\left(\underline{B}_{t}\right)+p\left(\Lambda_{t}\right)\right)= \\
& p\left(\Lambda_{t}\right)=p\left(A_{t}\right)-p\left(B_{t}\right)= \\
& p\left(b_{t}\right)+p\left(c_{t}\right)=\left(2 \times p\left(c_{t}\right)\right)+p\left(\Lambda_{t}\right)= \\
& \begin{array}{rr}
+ & 1-p\left(b_{t}\right)-p\left(c_{t}\right) \\
+ & p\left(c_{t}\right)+p\left(d_{t}\right)
\end{array} \\
& =p\left(B_{t}\right)+p\left(\underline{B}_{t}\right) \\
& =1-p\left(\underline{B}_{t}\right)+p\left(\Lambda_{t}\right) \\
& p\left(\underline{B}_{t}\right)-p\left(\Lambda_{t}\right) \\
& p\left(b_{t}\right)-p\left(c_{t}\right) \\
& 1-p\left(a_{t}\right)-p\left(d_{t}\right)
\end{aligned}
$$

while +1 denotes the normalized sample space of $A_{t}$ and $B_{t}$. Under conditions of Einstein's (A. Einstein, 1916) general (I. Barukčić, 2016c, 2016a) theory of relativity, $\Lambda$ indicates the cosmological "constant" (Albert Einstein, 1917). Einstein's field equations known as $R_{\mu \nu}-(\mathrm{R} / 2) \times \mathrm{g}_{\mu \nu}+\Lambda \times \mathrm{g}_{\mu \nu}=\left(4 \times 2 \pi \times \gamma / \mathrm{c}^{4}\right) \times \mathrm{T}_{\mu \nu}$ can be expressed in terms of probability theory as $\mathbf{p}\left(\mathbf{B}_{t}\right)+\mathbf{p}\left(\Lambda_{t}\right)=\mathbf{1}-\mathbf{p}\left(\mathbf{B}_{\mathbf{t}}\right)+\mathbf{p}\left(\Lambda_{\mathbf{t}}\right)=\mathbf{p}\left(\mathbf{A}_{\mathbf{t}}\right)$ at each point in space-time $t$ while $p\left(a_{t}\right), p\left(b_{t}\right)$, $p\left(c_{t}\right)$ and $p\left(d_{t}\right)$ may denote the four basic fields of nature. Multiplying by the Ricci tensor $R_{\mu v}$, we obtain the geometrized form of Einstein's field equation as $R_{\mu \nu}-p\left(B_{t}\right) \times R_{\mu \nu}+p\left(\Lambda_{t}\right) \times R_{\mu v}=p\left(A_{t}\right) \times R_{\mu \nu}$ where $p\left(A_{t}\right) \times R_{\mu \nu}=$ $\left(4 \times 2 \pi \times \gamma / c^{4}\right) \times T_{\mu \nu}$ and $p\left(B_{t}\right) \times R_{\mu \nu}=(R / 2) \times g_{\mu \nu}$ and $\Lambda \times g_{\mu \nu}=p\left(\Lambda_{t}\right) \times R_{\mu \nu}$. In this context, a probability tensor (I. Barukčić, 2016a) is needed. Under circumstances were the probability of an event is constant from trial to trial (i. e. Binomial distribution), the relationships before simplifies. We obtain some of the relationships per definitionem 


$$
\begin{array}{ccccc}
A & \equiv n \times p\left(a_{t}\right)+n \times p\left(b_{t}\right) & = & n \times p\left(A_{t}\right) \\
B & \equiv n \times p\left(a_{t}\right)+n \times p\left(c_{t}\right) & = & n \times p\left(B_{t}\right) \\
a & \equiv & n \times p\left(a_{t}\right) & = & n \times p\left(A_{t} \cap B_{t}\right) \\
b & n \times p\left(b_{t}\right) & & \\
c & n \times p\left(c_{t}\right) & & \\
d & n \times p\left(d_{t}\right) & & \\
n & \equiv & n \times p\left(a_{t}\right)+n \times p\left(b_{t}\right) & + & n \times p\left(c_{t}\right)+n \times p\left(d_{t}\right) \\
n & \equiv & n \times p\left(A_{t}\right)+n \times p\left(\underline{A}_{t}\right) & = & n \times p\left(B_{t}\right)+n \times p\left(\underline{B}_{t}\right)
\end{array}
$$

The meaning of the abbreviations a, b, c, d, n et cetera are explained by following 2 by 2-table (Table 2).

Table 2. The sample space of a contingency table

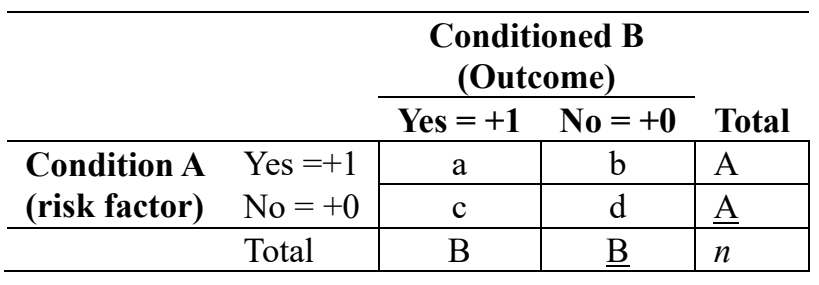

Definition 2.1.3 (Sufficient condition (conditio per quam))

The mathematical formula of the sufficient condition relationship of a population is defined as

$$
\begin{aligned}
p\left(A_{t} \rightarrow B_{t}\right) & \equiv \frac{(a)+(c)+(d)}{n}=1 \\
& \equiv p\left(a_{t}\right)+p\left(c_{t}\right)+p\left(d_{t}\right) \\
& \equiv p\left(a_{t}\right)+\left(1-p\left(A_{t}\right)\right) \\
& \equiv\left(p\left(B_{t}\right)+p\left(d_{t}\right)\right) \\
& \equiv
\end{aligned}
$$

Definition 2.1.4 (The $\mathrm{X}^{2}$ Test of Goodness of Fit of a Sufficient Condition)

The chi-square value of a conditio per quam relationship using the continuity correction (Yates, 1934), is derived (Barukčić, 2018) as

$$
X^{2}((A \rightarrow B) \mid A) \equiv \frac{((b)-(1 / 2))^{2}}{A}+0=0
$$

or alternatively as

$$
X^{2}((A \rightarrow B) \mid \underline{B}) \equiv \frac{((b)-(1 / 2))^{2}}{\underline{B}}+0=0
$$

Definition 2.1.5 (Necessary condition (conditio sine qua non))

The mathematical formula of the necessary condition relationship of a population is defined as 


$$
\begin{aligned}
p\left(A_{t} \leftarrow B_{t}\right) & \equiv \frac{(a)+(b)+(d)}{n}=1 \\
& \equiv p\left(a_{t}\right)+p\left(b_{t}\right)+p\left(d_{t}\right) \\
& \equiv p\left(a_{t}\right)+\left(1-p\left(B_{t}\right)\right) \\
& \equiv\left(p\left(A_{t}\right)+p\left(d_{t}\right)\right) \\
& \equiv
\end{aligned}
$$

\section{Definition 2.1.6 (The $\mathrm{X}^{2}$ Test of Goodness of Fit of a Necessary Condition)}

Using the continuity correction, the chi-square value of a conditio sine qua non distribution follows as

$$
X^{2}((A \leftarrow B) \mid B) \equiv \frac{((c)-(1 / 2))^{2}}{B}+0=0
$$

Depending upon the study design, another method to calculate the chi-square value of a conditio sine qua non distribution (while using the continuity correction) is defined as

$$
X^{2}((A \leftarrow B) \mid \underline{A}) \equiv \frac{((c)-(1 / 2))^{2}}{\underline{A}}+0=0
$$

Definition 2.1.7 (The exclusion relationship)

The mathematical formula of the exclusion relationship of a population is defined as

$$
\begin{aligned}
p\left(A_{t} \mid B_{t}\right) & \equiv \frac{(c)+(b)+(d)}{n}=1 \\
& \equiv p\left(c_{t}\right)+p\left(b_{t}\right)+p\left(d_{t}\right) \\
& \equiv p\left(c_{t}\right)+\left(1-p\left(B_{t}\right)\right) \\
& \equiv\left(1-p\left(A_{t}\right)+p\left(b_{t}\right)\right) \\
& \equiv
\end{aligned}
$$

Definition 2.1.8 (The $\mathrm{X}^{2}$ Test of Goodness of Fit of the Exclusion Relationship)

The chi square value with degree of freedom 2-1=1 of the exclusion relationship (Barukčić, 1989; Barukčić, 1997; Barukčić, 2005; Barukčić, 2006; Barukčić, 2009; Barukčić, 2011; Barukčić, 2012; Barukčić, 2016; Barukčić, 2017; Barukčić, 2018) with a continuity correction can be calculated as

$$
X^{2}((A \mid B) \mid A) \equiv \frac{((a)-(1 / 2))^{2}}{A}+0=0
$$

Depending upon the study design, another method to calculate the chi-square value of the exclusion relationship is defined as 


$$
X^{2}((A \mid B) \mid B) \equiv \frac{((a)-(1 / 2))^{2}}{B}+0=0
$$

The chi square Goodness of Fit Test of the exclusion relationship examines how well observed data compare with the expected theoretical distribution of an exclusion relationship.

Definition 2.1.9 (Necessary and sufficient condition)

The mathematical formula of the necessary and sufficient condition relationship of a population is defined as

$$
\begin{aligned}
p\left(A_{t} \leftrightarrow B_{t}\right) & \equiv & \frac{(a)+(d)}{n}=1 \\
& \equiv & p\left(a_{t}\right)+p\left(d_{t}\right) \\
& \equiv & \left(p\left(A_{t}\right)-p\left(b_{t}\right)\right)+\left(\left(1-p\left(A_{t}\right)\right)-p\left(c_{t}\right)\right) \\
& \equiv & \left(1-p\left(b_{t}\right)-p\left(c_{t}\right)\right) \\
& \equiv & +1 .
\end{aligned}
$$

Definition 2.1.10 (The $\mathrm{X}^{2}$ Test of Goodness of Fit of the necessary and sufficient condition)

Using the continuity correction, the chi-square value of the necessary and sufficient condition can be calculated as

$$
X^{2}(A \leftrightarrow B) \equiv \frac{((c)-(1 / 2))^{2}}{\mathrm{~B}}+\frac{((b)-(1 / 2))^{2}}{\underline{B}}=0
$$

The chi-square value of the necessary and sufficient condition distribution (while using the continuity correction) be defined as

$$
X^{2}(A \leftrightarrow B) \equiv \frac{((c)-(1 / 2))^{2}}{A}+\frac{((b)-(1 / 2))^{2}}{\underline{A}}=0
$$

Definition 2.1.11 (Either $\mathrm{A}_{\mathrm{t}}$ or $\mathrm{B}_{\mathrm{t}}$ relationship)

The mathematical formula of the either $A_{t}$ or $B_{t}$ relationship of a population is defined as

$$
\begin{array}{rlrl}
p\left(A_{t}>-<B_{t}\right) & \equiv & \frac{(b)+(c)}{n}=1 \\
& \equiv & p\left(b_{t}\right)+p\left(c_{t}\right) \\
& \equiv\left(p\left(A_{t}\right)-p\left(a_{t}\right)\right)+\left(\left(1-p\left(A_{t}\right)\right)-p\left(d_{t}\right)\right) \\
& \equiv & \left(1-p\left(a_{t}\right)-p\left(d_{t}\right)\right) \\
& \equiv
\end{array}
$$

Definition 2.1.12 (The $\mathrm{X}^{2}$ Test of Goodness of Fit of the either $\mathrm{A}_{t}$ or $\mathrm{B}_{\mathrm{t}}$ relationship)

Using the continuity correction, the chi-square value of the either $\mathrm{A}_{t}$ or $\mathrm{B}_{\mathrm{t}}$ relationship can be defined as 


$$
X^{2}(A>-<B) \equiv \frac{((a)-(1 / 2))^{2}}{\mathrm{~B}}+\frac{((d)-(1 / 2))^{2}}{\underline{B}}=0
$$

Another method to calculate the chi-square value of the either $\mathrm{A}_{t}$ or $\mathrm{B}_{\mathrm{t}}$ relationship (while using the continuity correction) can be defined as

$$
X^{2}(A>-<B) \equiv \frac{((a)-(1 / 2))^{2}}{A}+\frac{((d)-(1 / 2))^{2}}{\underline{A}}=0
$$

Definition 2.1.13 (The Chi-square goodness-of fit test of two single events)

The Chi-Square goodness-of fit test as proposed by Karl Pearson (Pearson, 1900) is of use in our everyday life too. Thus far, let $\mathrm{x}_{\mathrm{t}}$ denote the value of a random variable $\mathrm{X}$ at a certain point in space-time $\mathrm{t}$. Let us determine the value of the same random variable $\mathrm{X}$ under identical conditions some time later i. e. at the point in space-time $\mathrm{t}+1$. Has there been any significant change of the value of this single random variable from $t$ to $t+1$ ? The chi-square goodness of fit test can be applied to determine whether (sample distribution) data observed are consistent with (theoretical distribution) hypothesized data. The degrees of freedom (d.f.) of a chi-square goodness of fit test is equal to the number of levels ( $\mathrm{k}$ ) of the categorical variable minus 1 , in this case d.f. $=2-1=1$. In general, under these assumptions, the chi-square goodness of fit test is given by

$$
\mathrm{X}_{\text {Calculated }}^{2} \equiv \frac{\left(\left(x_{t+1}\right)-\left(x_{t}\right)\right)^{2}}{\left(x_{t}\right)}+\frac{\left(\left(x_{t}\right)-\left(x_{t}\right)\right)^{2}}{\left(x_{t}\right)}=\frac{\left(\left(x_{t+1}\right)-\left(x_{t}\right)\right)^{2}}{\left(x_{t}\right)}+0=0
$$

Example.

An Epstein-Barr virus (EBV) infection can be monitored to some extent by immunoglobulin G (IgG) antibodies to EBV viral capsid antigens (VCA). A physician is prescribing a drug regimen to cure an EBV infection and tries to get some evidence $(\alpha=.0455)$ whether the drugs prescribed are of any use. The EBV VCA IgG titer before the therapy was $100 \mathrm{I} . \mathrm{E} / \mathrm{ml} .(\mathrm{t}=1)$. After three months of therapy, the EBV titer declined to $50 \mathrm{I} . \mathrm{E} . / \mathrm{ml}$. Is the therapy of any use? The $\mathrm{X}^{2}$ critical at $\alpha=.0455$ is $\mathrm{X}^{2}$ (critical) $=4$. Thus far, if the $\mathrm{X}^{2}$ (calculated) is greater than 4 , there is some evidence that the therapy is of help, even if one single patient is regarded. We obtain the following result.

$$
\mathrm{X}_{\text {Calculated }}^{2} \equiv \frac{\left(\left(x_{t+1}\right)-\left(x_{t}\right)\right)^{2}}{\left(x_{t}\right)}+0=\frac{((100)-(50))^{2}}{(100)}+0=\frac{(2500)}{(100)}+0=25
$$

Conclusion. The therapy prescribed is of help. Thus far, a therapy which is of help for one patient, can be of help for other patients too.

Definition 2.1.14 (Independence)

In the case of independence (Kolmogoroff, 1933; Moivre, 1718) of $A_{t}$ and $B_{t}$ it is generally valid that

$$
p\left(A_{t} \cap B_{t}\right) \equiv p\left(A_{t}\right) \times p\left(B_{t}\right)
$$

Definition 2.1.15 (The Mathematical Formula of the Causal Relationship k)

The mathematical formula of the causal relationship k (I. Barukčić, 2018d, 1989, 2011, 2016b, 2016c, 2016c, 2017, 2018b, 2018c, 2018a, 2018d; K. Barukčić, Barukčić, \& Barukčić, 2018) is defined for every single event, at every single Bernoulli trial $\mathrm{t}$, as

$$
k\left(A_{t}, B_{t}\right) \equiv \frac{p\left(A_{t} \cap B_{t}\right)-\left(p\left(A_{t}\right) \times p\left(B_{t}\right)\right)}{\sqrt[2]{p\left(A_{t}\right) \times\left(1-p\left(A_{t}\right)\right) \times p\left(B_{t}\right) \times\left(1-p\left(B_{t}\right)\right)}}
$$

where $A_{t}$ denotes the cause and $B_{t}$ denotes the effect. Under some certain circumstances, the chi-square distribution can be applied to determine the significance of causal relationship k. Again, it necessary to point out that neither 
Pearson's concept of correlation $r$ nor Pearson's concept of $\phi$ is identical with causation. The mathematical formula of the causal relationship k has nothing to do with Pearson's methods and is not identical with Pearson's concept of correlation. This has been proved for many times and has been widely discussed in many publications too.

Definition 2.1.16 (The 95\% Confidence Interval of the Causal Relationship k)

The $95 \%$ interval for the causal relationship $\mathrm{k}$ was calculated by the formula

$$
\left\{k\left(A_{t}, B_{t}\right)-\sqrt[2]{\frac{5}{n}} ; k\left(A_{t}, B_{t}\right)+\sqrt[2]{\frac{5}{n}}\right\}
$$

Definition 2.1.17. (Index of unfairness)

The index of unfairness (IOU) is defined (I. Barukčić, 2019) as

$$
I O U \equiv\left(\left(\frac{A+B}{n}\right)-1\right)
$$

The range of $\mathrm{A}$ is $0 \leq \mathrm{A} \leq \mathrm{n}$, while the range of $\mathrm{B}$ is $0 \leq \mathrm{B} \leq \mathrm{n}$. A study design based on $\mathrm{A}=\mathrm{B}=0$ leads to an index of unfairness of IOU $=(((0+0) / n)-1)=-1$. A study design which demands that $A=B=n$ leads to an index of unfairness of IOU $=(((n+n) / n)-1)=+1$. In particular, the range of the index of unfairness is $[-1 ;+1]$. In this context let us define the following.

Definition 2.1.18 (The probability of an index of unfairness)

The probability of an unfairness $\mathrm{p}(\mathrm{IOU})$ is defined as

$$
p(I O U) \equiv \text { Absolute }\left(\left(\frac{A+B}{n}\right)-1\right)
$$

Definition 2.1.19 Index of independence (IOI)

The index of independence (IOI) is defined as

$$
I O I \equiv\left(\left(\frac{A+\underline{B}}{n}\right)-1\right)
$$

Definition 2.1.20 (The probability of an index of independence)

The probability of an index of independence $p(\mathrm{IOI})$ is defined as

$$
p(I O I) \equiv \text { Absolute }\left(\left(\frac{A+\underline{B}}{n}\right)-1\right)
$$

\subsection{Material}

Experiment 2.2.1 (Hot plate experiment)

Research on human participants requires protection at least according to the Declaration of Helsinki issued by the World Medical Association (Declaration of Helsinki, 1997). Among other, clearly formulated experimental protocols should be approved by independent ethical review boards (ethics committees and institutional review boards). The following experiments is only a thought experiment and there is no need for such an approval. Let $A_{t}$ denote a plate, a Binomial random variable, which can take only two values, either hot $=+1$ or not hot $=+0$. A hot plate is defined by the fact that the same damages a finger of a human being in a certain way without any hesitation. One property of a cold plate is that the same does not damage the finger of a human being in a certain way. Let $\mathrm{B}_{\mathrm{t}}$ denote an index finger of a human being, a Binomial random variable, which can take only two values, either injured $=+1$ or not injured $=+0$. Inclusion and exclusion criteria are defined. A placebo group is completely identical with the verum group. The experiments are independent and performed under the same conditions et cetera. 
Experiment 2.2.2 (Burning candle experiment)

Let $\mathrm{A}_{\mathrm{t}}$ denote gaseous oxygen, a Binomial random variable, which can take only two values, either gaseous oxygen present $=+1$ or not gaseous oxygen not present $=+0$. Gaseous oxygen present means that the amount is enough to assure that a candle can burn. Let $\mathrm{B}_{\mathrm{t}}$ denote a candle, a Binomial random variable, which can take only two values, either a candle is burning $=+1$ or a candle is not burning $=+0$.

\section{Results}

Theorem 1. (The index of independence)

\section{Claim.}

The primary motivation for a study design which investigates the relationship between the events $A_{t}$ and $B_{t}$ can be with good grounds, that the events $\mathrm{A}_{\mathrm{t}}$ and $\mathrm{B}_{\mathrm{t}}$ are independent of each other. Under the assumption of independence of $A_{t}$ from $B_{t}$ and vice versa study design is fair and the data are formally not self-contradictory due to study design if the index of independence (IOI) is

$$
I O I=\left(\frac{(A+\underline{B})}{n}-1\right)=+0
$$

\section{Proof.}

Under the assumption of independence (Kolmogoroff, 1933; Moivre, 1718), it is

$$
p\left(a_{t}\right) \equiv p\left(A_{t} \cap B_{t}\right)=p\left(A_{t}\right) \times p\left(B_{t}\right)
$$

Rearranging equation, we obtain

$$
\frac{p\left(A_{t} \cap B_{t}\right)}{p\left(A_{t}\right)}=p\left(B_{t}\right) \text { and equally } \frac{p\left(A_{t} \cap B_{t}\right)}{p\left(B_{t}\right)}=p\left(A_{t}\right)
$$

or

$$
\left(\left(\frac{p\left(A_{t} \cap B_{t}\right)}{p\left(A_{t}\right)}\right)-p\left(B_{t}\right)\right)=0 \text { and equally that }\left(\left(\frac{p\left(A_{t} \cap B_{t}\right)}{p\left(B_{t}\right)}\right)-p\left(A_{t}\right)\right)=0
$$

or

$$
\left(\left(\frac{p\left(A_{t} \cap B_{t}\right)}{p\left(A_{t}\right)}\right)-\frac{\left(p\left(A_{t}\right) \times \mathrm{p}\left(B_{t}\right)\right)}{p\left(A_{t}\right)}\right)=0 \text { and }\left(\left(\frac{p\left(A_{t} \cap B_{t}\right)}{p\left(B_{t}\right)}\right)-\frac{\left(p\left(A_{t}\right) \times \mathrm{p}\left(B_{t}\right)\right)}{p\left(B_{t}\right)}\right)
$$

or that

$$
\left(\frac{\left(p\left(A_{t} \cap B_{t}\right)\right)-\left(p\left(A_{t}\right) \times \mathrm{p}\left(B_{t}\right)\right)}{p\left(A_{t}\right)}\right)=0 \text { and }\left(\frac{\left(p\left(A_{t} \cap B_{t}\right)\right)-\left(p\left(A_{t}\right) \times \mathrm{p}\left(B_{t}\right)\right)}{p\left(B_{t}\right)}\right)
$$

In other words, under the condition of independence, study design should fulfill among other the requirement that

$$
\left(\frac{\left(p\left(A_{t} \cap B_{t}\right)\right)-\left(p\left(A_{t}\right) \times \mathrm{p}\left(B_{t}\right)\right)}{p\left(A_{t}\right)}\right)=\left(\frac{\left(p\left(A_{t} \cap B_{t}\right)\right)-\left(p\left(A_{t}\right) \times \mathrm{p}\left(B_{t}\right)\right)}{p\left(B_{t}\right)}\right)
$$

We define

$$
X_{t} \equiv\left(p\left(A_{t} \cap B_{t}\right)\right)-\left(p\left(A_{t}\right) \times \mathrm{p}\left(B_{t}\right)\right)
$$


while the term is of no further importance for us in this context. The equation above simplifies as

$$
\left(\frac{X_{t}}{p\left(A_{t}\right)}\right)=\left(\frac{X_{t}}{p\left(B_{t}\right)}\right)
$$

or as

$$
X_{t} \times p\left(B_{t}\right)=X_{t} \times p\left(A_{t}\right)
$$

Under conditions, where the division by $X_{t}$ is not possible we define $X_{t}=+1$. After the division by $X_{t}$ the equation before simplifies to

$$
p\left(B_{t}\right)=p\left(A_{t}\right)
$$

In general, it is $\mathrm{p}\left(\mathrm{A}_{\mathrm{t}}\right)=1-\mathrm{p}\left(\underline{A}_{t}\right)$ or $\mathrm{p}\left(\mathrm{B}_{\mathrm{t}}\right)=1-\mathrm{p}\left(\underline{B}_{t}\right)$. The equation before changes to

$$
p\left(B_{t}\right)=1-p\left(\underline{A}_{t}\right)
$$

and to

$$
p\left(\underline{A}_{t}\right)+p\left(B_{t}\right)=+1
$$

or to

$$
p\left(A_{t}\right)=1-p\left(\underline{B}_{t}\right)
$$

and to

$$
p\left(\underline{B}_{t}\right)+p\left(A_{t}\right)=+1
$$

In point of fact, there are many ways to design a study, design which assumes the independence of the events $A_{t}$ and $\mathrm{B}_{\mathrm{t}}$ demands under conditions of a Bernoulli distribution that

$$
p\left(\underline{A}_{t}\right)+p\left(B_{t}\right)-1=0
$$

Multiplying by $\mathrm{n}$, the sample size, the index of independence follows as

$$
\frac{n \times\left(p\left(\underline{A}_{t}\right)+p\left(B_{t}\right)\right)}{n}-1=0
$$

Under conditions of a Binomial distribution, it is $\underline{A}=n \times p\left(\underline{A}_{t}\right), B=n \times p\left(B_{t}\right)$. We obtain

$$
I O I=\frac{A}{n}-1=0
$$

or equally as

$$
I O I=\left(\frac{(A+\underline{\mathrm{B}})}{n}-1\right)=+0
$$

\section{Quod erat demonstrandum.}

Remark 1 .

An index of independence of IOI $=0$ indicates a study design which supports the assumption of an independence of the events $A_{t}$ and $B_{t}$.

Theorem 2. (The probability of an index of independence)

\section{Claim.}

The probability of an index of independence, denoted as $\mathrm{p}(\mathrm{IOI})$, is

$$
p(I O I)=\operatorname{Absolute}\left(p\left(A_{t}\right)+p(\underline{\mathrm{B}})-\left(p\left(A_{t}\right)+p\left(\underline{A}_{t}\right)\right)\right)
$$




\section{Proof.}

The index of independence was derived as

$$
I O I=\left(\frac{(A+\underline{B})}{\mathrm{n}}-1\right)
$$

Under conditions of a Binomial distribution, it is $A=n \times p\left(A_{t}\right), \underline{B}=n \times p\left(\underline{B}_{t}\right)$ while equally it is $1=p\left(A_{t}\right)+p\left(\underline{A}_{t}\right)$ or $1=p\left(B_{t}\right)+p\left(\underline{B}_{t}\right)$. The index of independence changes under these circumstances to

$$
I O I=\left(\frac{\left(\mathrm{n} \times p\left(A_{t}\right)+\mathrm{n} \times p(\underline{\mathrm{B}})\right)}{\mathrm{n}}-\frac{\mathrm{n} \times\left(p\left(A_{t}\right)+p\left(\underline{A}_{t}\right)\right)}{n}\right)
$$

Simplifying, it is

$$
I O I=\left(p\left(A_{t}\right)+p(\underline{B})-\left(p\left(A_{t}\right)+p\left(\underline{A}_{t}\right)\right)\right)
$$

The index of independence indicates a probability measure. To date, probability is a positive number between +0 and +1 , including both numbers. Therefore, we define the probability of an index of independence $p(I O I)$ as

$$
p(I O I)=\operatorname{Absolute}\left(p\left(A_{t}\right)+p(\underline{\mathrm{B}})-\left(p\left(A_{t}\right)+p\left(\underline{A}_{t}\right)\right)\right)=\text { Absolute }(I O I)
$$

\section{Quod erat demonstrandum.}

Remark 2.

The lower the probability $\mathrm{p}(\mathrm{IOI})$, the more a study design is able provide evidence of the independence of the events $\mathrm{A}_{t}$ and $\mathrm{B}_{\mathrm{t}}$.

Theorem 3. (The index of unfairness IOU and the causal relationship k)

\section{Claim.}

A study with a certain study design which investigates the causal relationship between $A_{t}$ and $B_{t}$ should assure as much as possible an IOU near or equal to 0 or

$$
\operatorname{IOU}=\left(\left(\frac{A+B}{n}\right)-1\right) \approx 0
$$

to reduce the effect of publication bias on the results and conclusions drawn from a systematic review and metaanalyses with respect to causation.

\section{Proof.}

In the case of a causal relationship given, it is

$$
\begin{aligned}
\left|k\left(A_{t}, B_{t}\right)\right| \equiv & \frac{p\left(A_{t} \cap B_{t}\right)-\left(p\left(A_{t}\right) \times p\left(B_{t}\right)\right)}{\sqrt[2]{p\left(A_{t}\right) \times\left(1-p\left(A_{t}\right)\right) \times p\left(B_{t}\right) \times\left(1-p\left(B_{t}\right)\right)}} \\
& =\frac{\sigma\left(A_{t}, B_{t}\right)}{\sigma\left(A_{t}\right) \times \sigma\left(B_{t}\right)} \equiv+1
\end{aligned}
$$

In this context, we define without any changes of the content itself the following. 


$$
\begin{aligned}
S & \equiv & p\left(A_{t} \cap B_{t}\right)-\left(p\left(A_{t}\right) \times p\left(B_{t}\right)\right) \\
T & \equiv & p\left(A_{t}\right) \times\left(1-p\left(A_{t}\right)\right) \\
U & \equiv & p\left(B_{t}\right) \times\left(1-p\left(B_{t}\right)\right)
\end{aligned}
$$

The mathematical formula of the causal relationship $\mathrm{k}$ simplifies as

$$
\begin{aligned}
\left|k\left(A_{t}, B_{t}\right)\right| \equiv & \frac{p\left(A_{t} \cap B_{t}\right)-\left(p\left(A_{t}\right) \times p\left(B_{t}\right)\right)}{\sqrt[2]{p\left(A_{t}\right) \times\left(1-p\left(A_{t}\right)\right) \times p\left(B_{t}\right) \times\left(1-p\left(B_{t}\right)\right)}} \\
& =\frac{S}{\sqrt[2]{T \times U}} \equiv+1
\end{aligned}
$$

In the case of a given causal relationship, it is

$$
\frac{S^{2}}{T \times U}=\equiv\left|k\left(A_{t}, B_{t}\right)\right|^{2}=+1
$$

Rearranging equation, we obtain

$$
S^{2} \equiv T \times U \times 1
$$

Rearranging equation again, we obtain

$$
\frac{S^{2}}{T}=U \text { and } \frac{S^{2}}{U}=T
$$

or

$$
\left(\left(\frac{S^{2}}{T}\right)-U\right)=0 \text { and that }\left(\left(\frac{S^{2}}{U}\right)-T\right)=0
$$

or

$$
\left(\left(\frac{S^{2}}{T}\right)-\frac{T \times U}{T}\right)=0 \text { and that }\left(\left(\frac{S^{2}}{U}\right)-\frac{T \times U}{U}\right)=0
$$

or that

$$
\left(\frac{S^{2}-(T \times U)}{T}\right)=0 \text { and that }\left(\frac{S^{2}-(T \times U)}{U}\right)=0
$$

Under these circumstances, a study design should fulfill the requirement that

$$
\left(\frac{S^{2}-(T \times U)}{T}\right)=\left(\frac{S^{2}-(T \times U)}{U}\right)=0
$$

Rearranging equation, it is

$$
\left(S^{2}-(T \times U)\right) \times U=\left(S^{2}-(T \times U)\right) \times T
$$

We define

$$
X_{t} \equiv\left(S^{2}-(T \times U)\right)
$$


The equation above simplifies as

$$
X_{t} \times U=X_{t} \times T
$$

The goal of a study design is not to assure a certain value $X_{t}$. Thus far, the variable $X_{t}$ can be positive, negative or even equal to zero, the value of the same is not restricted. Under conditions, where the division by $\mathrm{X}_{\mathrm{t}}$ is not possible we define $X_{t}=+1$. After the division by $X_{t}$ the equation before simplifies to

$$
U=T
$$

or to

$$
p\left(B_{t}\right) \times\left(1-p\left(B_{t}\right)\right)=p\left(A_{t}\right) \times\left(1-p\left(A_{t}\right)\right)
$$

According to today's valid rules $($ negative $\times$ positive $=$ negative $)$ it is

$$
p\left(B_{t}\right)-p\left(B_{t}\right)^{2}=p\left(A_{t}\right)-p\left(A_{t}\right)^{2}
$$

or

$$
p\left(A_{t}\right)^{2}-p\left(B_{t}\right)^{2}=p\left(A_{t}\right)-p\left(B_{t}\right)
$$

Based on today's understanding of the binomial theorem (or binomial expansion) it is

$$
p\left(A_{t}\right)^{2}-p\left(B_{t}\right)^{2}=\left(p\left(A_{t}\right)-p\left(B_{t}\right)\right) \times\left(p\left(A_{t}\right)+p\left(B_{t}\right)\right)
$$

Simplifying equation, we obtain

$$
\left(p\left(A_{t}\right)-p\left(B_{t}\right)\right) \times\left(p\left(A_{t}\right)+p\left(B_{t}\right)\right)=p\left(A_{t}\right)-p\left(B_{t}\right)
$$

Under conditions where $\left(p\left(A_{t}\right)-p\left(B_{t}\right)\right)=0$, we define $\left(p\left(A_{t}\right)-p\left(B_{t}\right)\right)=+1$. Thus far, dividing by $\left(p\left(A_{t}\right)-p\left(B_{t}\right)\right)$, it is

$$
\left(p\left(A_{t}\right)+p\left(B_{t}\right)\right)=+1
$$

Multiplying by the sample size $\mathrm{n}$, it follows that

$$
\left(n \times p\left(A_{t}\right)\right)+\left(n \times p\left(B_{t}\right)\right)=n
$$

Under conditions of a Binomial distributed random variable, it is $n \times p\left(A_{t}\right)=A$ and $n \times p\left(B_{t}\right)=B$. The equation before becomes

$$
A+B=n
$$

Dividing by $\mathrm{n}$, it is

$$
\frac{A+B}{n}=+1
$$

Simplifying, we obtain

$$
\left(\frac{A+B}{n}\right)-1=0
$$

or 


$$
I O U=\left(\left(\frac{A+B}{n}\right)-1\right)=0
$$

\section{Quod erat demonstrandum.}

\section{Remark 3.}

Systematic reviews and meta-analyses are a very useful method for generating some evidence from different studies and to draw reliable conclusions. However, are there any factors which have influence on the chance of a study being published by a scientific journal? Many times, statistically significant results are more likely to be published, causing publication bias in meta-analysis of published studies (Kicinski, Springate, \& Kontopantelis, 2015). An important aspect of a rigorous systematic review is detecting publication bias and preventing an incorrect conclusion and reducing the negative effect of publication bias on the results and conclusions of systematic reviews and meta-analyses (Sutton, Duval, Tweedie, Abrams, \& Jones, 2000). IOU or the index of unfairness is one possible approach to deal with publication bias. Under conditions where the causal relationship $\mathrm{k}$ between the cause $\mathrm{A}_{\mathrm{t}}$ and an effect $\mathrm{B}_{\mathrm{t}}$ is analyzed, the study design should assure an IOU as near as possible to 0 . More precisely, a study design of a study grounded on a very low IOU is more appropriate to analyze the data for a causal relationship $\mathrm{k}$ and to assure that the results and conclusions of systematic reviews and meta-analyses drawn are not potentially biased.

Theorem 4. (The probability of an index of unfairness)

\section{Claim.}

The probability of an index of unfairness, denoted by $\mathrm{p}(\mathrm{IOU})$, is

$$
p(I O U)=\text { Absolute }(I O U)
$$

\section{Proof.}

The index of unfairness was derived as

$$
I O U=\left(\frac{(A+B)}{\mathrm{n}}-1\right)
$$

Under conditions of a Bernoulli distribution, it is $A=n \times p\left(A_{t}\right), \underline{B}=n \times p\left(\underline{B}_{t}\right)$ while $1=p\left(A_{t}\right)+p\left(\underline{A}_{t}\right)$ or $1=p\left(B_{t}\right)+$ $\mathrm{p}\left(\underline{B}_{t}\right)$. The index of unfairness changes under these circumstances to

$$
I O U=\left(\frac{\left(\mathrm{n} \times p\left(A_{t}\right)+\mathrm{n} \times p\left(B_{t}\right)\right)}{\mathrm{n}}-\frac{\mathrm{n} \times\left(p\left(A_{t}\right)+p\left(\underline{A}_{t}\right)\right)}{n}\right)
$$

Simplifying, it is

$$
I O U=\left(p\left(A_{t}\right)+p\left(B_{t}\right)-\left(p\left(A_{t}\right)+p\left(\underline{A}_{t}\right)\right)\right)
$$

The index of unfairness indicates a probability measure. To date, as stated before, probability is a positive number between +0 and +1 , including both numbers. Therefore, we define the probability of an index of unfairness something as

$$
p(I O U)=\text { Absolute }\left(p\left(A_{t}\right)+p\left(B_{t}\right)-\left(p\left(A_{t}\right)+p\left(\underline{A}_{t}\right)\right)\right)=\text { Absolute }(\text { IOU })
$$

\section{Quod erat demonstrandum.}

Remark 4.

The higher the probability $\mathrm{p}(\mathrm{IOU})$, the more unfair a study design and the greater the possibility that the data are 
probably biased and potentially inappropriate for causal analysis.

Theorem 3.5 (Study design and the causal relationship k)

Several experiments with different study design were performed. The following data were obtained and are presented by the following 2 by 2-tables (Table 3, Table 4, Table 5). A very fair experiment is illustrated by the Table 3.

Table 3. The relationship between a plate and a finger

\begin{tabular}{lc|c|c|l|}
\hline & & \multicolumn{2}{c}{ Finger injured } & \\
\cline { 3 - 4 } & & \multicolumn{1}{c}{ Yes $=+\mathbf{1}$} & \multicolumn{1}{c}{ No $=+\mathbf{0}$} & Total \\
\hline \multirow{2}{*}{ Hot Plate } & Yes $=+1$ & 50 & 0 & 50 \\
\cline { 3 - 4 } & No $=+0$ & 0 & 50 & 50 \\
\hline & Total & 50 & 50 & 100 \\
\hline
\end{tabular}

An extremely unfair experiment is illustrated by table 4 .

Table 4. The relationship between a plate and a finger

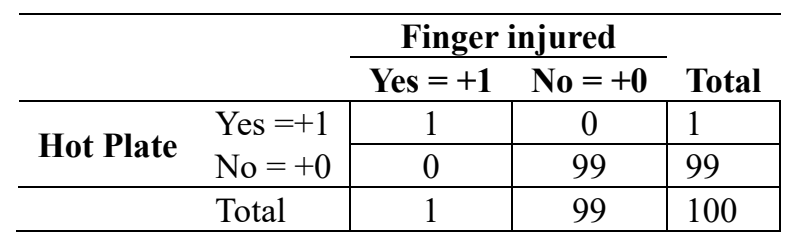

Another extremely unfair experiment is illustrated by table 5 .

Table 5. The relationship between a plate and a finger

\begin{tabular}{|c|c|c|c|c|}
\hline & & \multicolumn{2}{|c|}{ Finger injured } & \multirow[b]{2}{*}{ Total } \\
\hline & & Yes $=+1$ & $\mathrm{No}_{\mathrm{o}}=+\mathbf{0}$ & \\
\hline \multirow{3}{*}{ Hot Plate } & Yes $=+1$ & 99 & 0 & 99 \\
\hline & $\mathrm{No}=+0$ & 0 & 1 & 1 \\
\hline & Total & 99 & 1 & 100 \\
\hline
\end{tabular}

\section{Claim.}

A $p(I O U)=p(I O I)=0$ assures the recognition of causal relationships.

\section{Proof.}

The data above are tested for significance. The data of the table 3 are analyzed and presented by table 5 . The data of the table 4 are analyzed and presented by table 6 . The data of the table 5 are analyzed and presented by table 7 .

Table 5. The statistical analysis of the data of table 3

\begin{tabular}{|c|c|c|}
\hline & $p(I O U)=0,000$ & $p(I O I)=0,000$ \\
\hline $\mathrm{k}=+1$ & & \\
\hline$P$ value $(k \mid H G D)=9,9117 \mathrm{E}-30$ & Chi Sq. $(k)=100,000$ & \\
\hline $\mathrm{p}(\mathrm{SINE})=1$ & Chi Sq. $1($ SINE $)=0,000$ & Chi Sq. 2(SINE) $=0,000$ \\
\hline $\mathrm{p}(\mathrm{IMP})=1$ & Chi Sq. $1(\mathrm{IMP})=0,000$ & Chi Sq. 2 (IMP) $=0,000$ \\
\hline $\mathrm{p}(\mathrm{EXCL})=0,5$ & Chi Sq. $1(\mathrm{EXCL})=50,000$ & Chi Sq. 2(EXCL) $=50,000$ \\
\hline
\end{tabular}

The data as provided by table 4 are extremely unfair. 
Table 6. The statistical analysis of the data of table 4

$$
\begin{aligned}
\mathrm{k} & =+1 \\
\text { P value }(\mathrm{k} \mid \mathrm{HGD}) & =0,01 \\
\mathrm{p}(\mathrm{SINE}) & =1 \\
\mathrm{p}(\mathrm{IMP}) & =1 \\
\mathrm{p}(\mathrm{EXCL}) & =0,99
\end{aligned}
$$

$$
p(I O U)=0,980
$$

$\mathrm{p}(\mathrm{IOI})=0,000$

Chi Sq. $(k)=100,000$

Chi Sq. $1(\mathrm{SINE})=0,000$

Chi Sq. 1(IMP) $=0,000$

Chi Sq. 1(EXCL $)=1,000$

\begin{tabular}{|c|c|c|}
\hline & $p(I O U)=0,980$ & $p(I O I)=0,000$ \\
\hline \multicolumn{3}{|l|}{$\mathrm{k}=+1$} \\
\hline$P$ value $(k \mid H G D)=0,01$ & Chi Sq. $(k)=100,000$ & \\
\hline $\mathrm{p}(\mathrm{SINE})=1$ & Chi Sq. $1($ SINE $)=0,000$ & Chi Sq. 2 (SINE) $=0,000$ \\
\hline $\mathrm{p}(\mathrm{IMP})=1$ & Chi Sq. $1(\mathrm{IMP})=0,000$ & Chi Sq. $2($ IMP $)=0,000$ \\
\hline $\mathrm{p}(\mathrm{EXCL})=0,99$ & Chi Sq. 1(EXCL $)=99,000$ & Chi Sq. $2(E X C L)=99,000$ \\
\hline
\end{tabular}

Chi Sq. $2($ SINE $)=0,000$

Chi Sq. 2(IMP) $=0,000$

Chi Sq. 2(EXCL) $=1,000$

Due to the study design, the data as provided by table 5 are extremely unfair too.

Table 7. The statistical analysis of the data of table 5

The results as presented by Table 5 are self-evident. The causal relationship $\mathrm{k}=+1$, the $\mathrm{P}$ value calculated according to the hypergeometric distribution is $\mathrm{P}$ value $=9,9117 \mathrm{E}-30, \mathbf{p}(\mathbf{I O U})=\mathbf{p}(\mathbf{I O I})=\mathbf{0}$. The necessary condition is given $($ Chi Sq. $1(\mathrm{SINE})=0,000$; Chi Sq. $2(\mathrm{SINE})=0,000)$ and at the same time, the sufficient condition is given $($ Chi Sq. $1(\mathrm{IMP})=0,000$; Chi Sq. 2(IMP) $=0,000)$ too. A perfect study design should assure as much as possible an $\mathrm{p}(\mathrm{IOU})=\mathrm{p}(\mathrm{IOI})$ equal or very near to zero. As we can see, a significant causal relationship alone without an evidence of a significant conditio sine qua non relationship or a significant conditio per quam relationship or a significant exclusion relationship et cetera is an indicator of biased data and not that much of secured findings. However, the motivation of a researcher and other factors can influence the study design with the consequence that even contradictory data can be achieved (Table 6). The index of unfairness is extremely unfair with $\mathrm{p}(\mathrm{IOU})=$ 0,98 while $\mathrm{p}(\mathrm{IOI})=0$. Even under these very extreme conditions, theoretically, it is possible to recognize a causal relationship $(\mathrm{k}=+1, \mathrm{P}$ value $=0,01)$. The necessary condition is given $(\mathrm{Chi}$ Sq. $1(\mathrm{SINE})=0,000$; Chi Sq. 2(SINE) $=0,000)$ and at the same time, the sufficient condition is given (Chi Sq. $1(\mathrm{IMP})=0,000$; Chi Sq. $2(\mathrm{IMP})=0,000)$ too. In particular, the exclusion relationship is significant too (Chi Sq. $1(\mathrm{EXCL})=1,000$; Chi Sq. 2(EXCL) $=$ $1,000)$ which is a contradiction. Logically, it is not possible, that $A_{t}$ excludes $B_{t}$ and vice versa and that equally $A_{t}$ is a necessary condition of $\mathrm{B}_{\mathrm{t}}$. A p (IOU) which is much greater than $\mathrm{p}(\mathrm{IOI})$ can imply contradictions. In such cases, the use of the causal relationship is of help. A causal relationship which is greater 0 excludes a significant exclusion relationship. The reason is that in the case of an exclusion relationship $p\left(a_{t}\right)=p\left(A_{t} \cap B_{t}\right)=0$ and the causal relationship k derived at every single event, at every single Bernoulli trial $t$, as

$$
k\left(A_{t}, B_{t}\right) \equiv \frac{p\left(A_{t} \cap B_{t}\right)-\left(p\left(A_{t}\right) \times p\left(B_{t}\right)\right)}{\sqrt[2]{p\left(A_{t}\right) \times\left(1-p\left(A_{t}\right)\right) \times p\left(B_{t}\right) \times\left(1-p\left(B_{t}\right)\right)}}
$$

where $A_{t}$ denotes the cause and $B_{t}$ denotes the effect and reduces under these circumstances to

$$
k\left(A_{t}, B_{t}\right) \equiv \frac{0-\left(p\left(A_{t}\right) \times p\left(B_{t}\right)\right)}{\sqrt[2]{p\left(A_{t}\right) \times\left(1-p\left(A_{t}\right)\right) \times p\left(B_{t}\right) \times\left(1-p\left(B_{t}\right)\right)}}<0
$$

A significant exclusion relationship demands a negative causal relationship $\mathrm{k}$. Another way to circumvent problems like these is to assure a study design where $\mathbf{a}=\mathbf{d}$.

\section{Quod erat demonstrandum.}

Theorem 3.6 (Biased data and the causal relationship k)

The experiments of theorem before were performed under ideal conditions. In real life bias of different kind must be considered. We analyze the same relationship with data which are biased due to several causes. The following 
data which are biased were obtained and are presented by the following 2 by 2-tables (Table 8, Table 9, Table 10). A very fair experiment is illustrated by the Table 8 .

Table 8 . The relationship between a plate and a finger

\begin{tabular}{ll|c|c|l}
\hline & & \multicolumn{2}{c}{ Finger injured } & \multicolumn{1}{c}{ Total } \\
\cline { 3 - 4 } & & Yes $=+\mathbf{1}$ & \multicolumn{1}{c}{ No $=+\mathbf{0}$} & \multicolumn{1}{c}{ Totan } \\
\hline \multirow{2}{*}{ Hot Plate } & Yes $=+1$ & 1 & 0 & 1 \\
\cline { 3 - 4 } & No $=+0$ & 49 & 50 & 99 \\
\hline & Total & 50 & 50 & 100 \\
\hline
\end{tabular}

An extremely unfair experiment is illustrated by table 9 too.

Table 9. The relationship between a plate and a finger

\begin{tabular}{lc|c|c|l|}
\hline & & \multicolumn{2}{c}{ Finger injured } & \multicolumn{1}{c}{ Total } \\
\cline { 3 - 4 } & & \multicolumn{1}{c}{ Yes $=+\mathbf{1}$} & \multicolumn{1}{c}{ No $=+\mathbf{0}$} & \multicolumn{1}{c}{ Tos $=+1$} \\
\multirow{2}{*}{ Hot Plate } & 49 & 49 & 98 \\
\cline { 3 - 4 } & No $=+0$ & 1 & 1 & 2 \\
\hline & Total & 50 & 50 & 100 \\
\hline
\end{tabular}

Another extremely biased experiment is illustrated by table 10 .

Table 10. The relationship between a plate and a finger

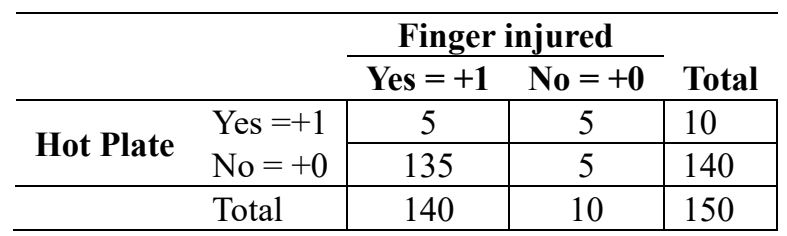

\section{Claim.}

A high $\mathrm{p}(\mathrm{IOU})$ and a high $\mathrm{p}(\mathrm{IOI})$ need not to exclude the recognition of conditions. A p(IOI) $<0,5$ appears to be necessary to recognize with an appropriate degree of certainty causal relationships while an $\mathrm{p}(\mathrm{IOI})<0,25$ is of great help in analysing causal data. The higher $\mathrm{p}(\mathrm{IOI})$ the less are the data suiteable for causal analysis.

\section{Proof.}

The data are tested again for significance. The statistical analysis of the data of the table 8 is presented by table 11 .

Table 11. The statistical analysis of the data of table 8

\begin{tabular}{|c|c|c|c|c|}
\hline & & $p(I O U)=0,490$ & $\mathbf{p}(\mathrm{IOI})=$ & 0,490 \\
\hline \multicolumn{5}{|c|}{$k=+0,10050378$} \\
\hline$P$ value $(k \mid$ HGD) $=$ & 0,5 & Chi Sq. $(\mathrm{k})=1,010$ & & \\
\hline $\mathrm{p}(\mathrm{SINE})=$ & 0,51 & Chi Sq. 1(SINE) $=48,020$ & Chi Sq. 2(SINE) $=$ & 24,253 \\
\hline $\mathrm{p}(\mathrm{IMP})=$ & 1 & Chi Sq. $1($ IMP $)=0,000$ & Chi Sq. 2(IMP) = & $\mathbf{0 , 0 0 0}$ \\
\hline $\mathrm{p}(\mathrm{EXCL})=$ & 0,99 & Chi Sq. 1(EXCL) $=0,020$ & Chi Sq. 2(EXCL) $=$ & 1,000 \\
\hline
\end{tabular}

We are reanalyzing a secured causal relationship between a hot plate and an injured human finger. However, a study design provided data which are biased and only of limited value. The study of Table 8 has an $\mathbf{p}(\mathbf{I O U})=$ $\mathbf{p}($ IOI $)=\mathbf{0 , 4 9}$ but we have not been able to recognize a significant causal relationship $(\mathrm{k}=+0,101 ; \mathrm{P}$ value $=0,5)$ even if a causal relationship in the population between a hot plate and an injured human finger is given for sure. Thus far, it is not enough that $p(I O U)=p(I O I)$ to be able to consider data for a causal analysis. The study design should assure that both, $\mathrm{p}(\mathrm{IOU})$ and $\mathrm{p}(\mathrm{IOI})$, should be as near as possible to zero. Briefly, that the data are biased can be recognized by the fact that both is significant, the conditio per quam (Chi Sq. 1(IMP) $=0,000$; Chi Sq. $2(\mathrm{IMP})=0,000)$ and the exclusion relationship (Chi Sq. 1(EXCL) $=0,020$; Chi Sq. 2(EXCL) $=1,000)$. This is a contradiction; we just cannot decide what is correct. Such data cannot be considered for a statistical analysis or 
the causal relationship k must decide what is correct or what could be correct. A significant conditio per quam relationship demands a positive causal relationship $k$. In other words, if such data should be used for further analysis, we should conclude due to preliminary reasons that there is a significant conditio per quam relationship and not a significant exclusion relationship. However, a high $\mathrm{p}(\mathrm{IOU})$ and a high $\mathrm{p}(\mathrm{IOI})$ indicates potentially biased data. In this context, the statistical analysis of the data of the table 9 is presented by table 12 .

Table 12. The statistical analysis of the data of table 9

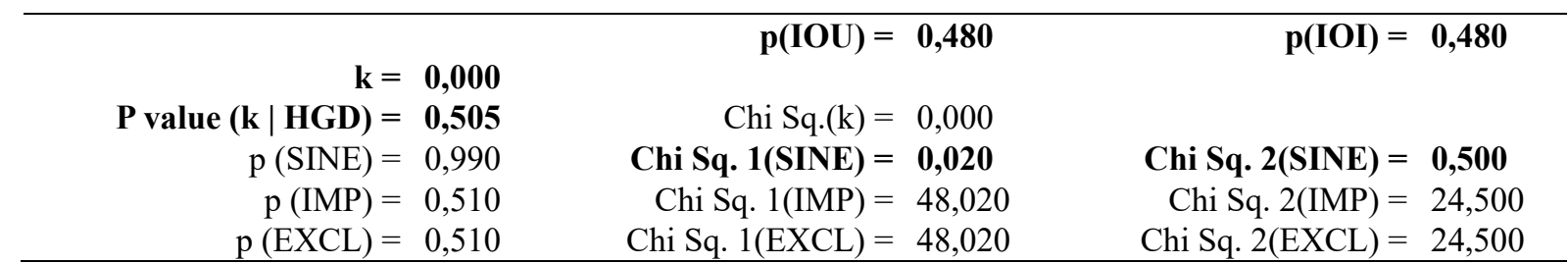

The causal relationship between a hot plate and an injured human finger is secured and clear. Still, if we rely on the data of the study above (Table 9) there is no causal relationship between a hot plate and an injured human finger $(\mathrm{k}=+0 ; \mathrm{P}$ vlaue $=0,505)$. The conclusion cannot be that we are just not able to recognize causal relationships by statistical methods. Among other, the study design technology must be improved to ensure the quality of data. A high $p(I O U)$ and a high $p(I O I)$ may exclude the recognition of causal relationships but not the recogniztion of conditions too. Even under these very unfair conditions it was possible to recognize that there is a significant conditio sine qua non relationship. Extremely biased data are presented by table 10 . The statistical analysis of the same data is presented by table 13 .

Table 13. The statistical analysis of the data of table 10

\begin{tabular}{|c|c|c|c|c|}
\hline & & $p(I O U)=$ & $\mathbf{0 , 0 0 0}$ & $p(I O I)=0,867$ \\
\hline $\mathbf{k}=$ & $-0,464$ & & & \\
\hline$P$ value $(k \mid$ HGD) $=$ & $\mathbf{0 , 0 0 0}$ & Chi Sq. $(\mathrm{k})=$ & 32,334 & \\
\hline $\mathrm{p}(\mathrm{SINE})=$ & 0,100 & Chi Sq. $1($ SINE $)=$ & 130,179 & Chi Sq. $2($ SINE $)=130,179$ \\
\hline p $($ IMP $)=$ & 0,967 & Chi Sq. $1($ IMP $)=$ & 2,500 & Chi Sq. 2(IMP) $=2,500$ \\
\hline $\mathrm{p}\left(\mathrm{SINE}^{\wedge} \mathrm{IMP}\right)=$ & 0,067 & Chi Sq. $1\left(\right.$ SINE $\left.^{\wedge} \mathrm{IMP}\right)=$ & 132,679 & Chi Sq. $1\left(\mathrm{SINE}^{\wedge} \mathrm{IMP}\right)=132,679$ \\
\hline$p(E X C L)=$ & 0,967 & Chi Sq. 1(EXCL $)=$ & $\mathbf{0 , 1 7 9}$ & Chi Sq. 2(EXCL) $=2,500$ \\
\hline
\end{tabular}

Table 10 presents data of a secured relationship between a hot plate and an injured human finger. Due to several factors, studies may produce biased data with the consequence that the same are only of a very limmited or of none value. This is demonstrated by the statistical analysis (Table 13) of the data of table 10. The data published support the position that there is a highly significant negative causal relationship between a hot plate and an injured human finger $(\mathrm{k}=-0,464$; P value $=0,000)$ while at the same time the exclusion relationship (Chi Sq. 1(EXCL) $=0,179$; Chi Sq. $2(\mathrm{EXCL})=2,500)$ is significant too. We would have to recognize: $A$ hot plate prevents form an injured human finger while such a conclusion is not completely illogical. Human subject have a free will and do know that a hot plate can damage the finger. Therefore, the most persons refused to put their own finger on a hot plate. Only 5/10 had the courage to put their finger on a hot plate. In toto $135 / 140$ had an injured finger but due to another cause and not due to a hot plate. The same data provide at the same time evidence of a significant conditio sine qua non relationship $(\mathrm{p}(\mathrm{IMP})=0,967$; Chi Sq. $1(\mathrm{IMP})=2,500$; Chi Sq. 2(IMP) $=2,500$ ) too. These data are selfcontradictory, we just cannot decide for sure what is correct? How can data provide at the same time evidence of two each other exluding relationships? The $p(I O U)=0$ indicates that the analysis of conditions is possible. Contrary to expectation, $p(I O I)=0,867$ indicates that the analysis of causal relationships does not make any sense because it cannot be excluded that the data are biased too much. Due to the self-contradictory data, we just cannot decide what is true and what is not true. Such data should be excluded from analysis until a more precise technology is known how to deal with such kind of data.

A $p($ IOI $)<0,5$ appears to enable the recognition of causal relationships while an $p(I O I)<0,25$ is of great help in analysing causal data. The higher $\mathrm{p}(\mathrm{IOI})$ the less are the data suiteable for causal analysis. 


\section{Quod erat demonstrandum.}

Theorem 3.7 (Without oxygen no burning candle)

The relationship between the behavior of a candle produced out of wax and oxygen is studied. The investigator lights the candle wick of many candles (old, young, big, small, red, green, curved, straight et cetera) under different conditions. Candle flame reacts with oxygen such that heat and light which characterizes a candle are produced. The verum group is studied under conditions of the air we breathe, i. e. about 21 percent oxygen. The placebo group is studied under conditions where no oxygen present. Fire itself needs at least 16 percent oxygen. Below that the fire will go out. In the following, a burning candle is enclosed and hermetically sealed by an appropriate cup of transparent glass while at the same time the concentration of oxygen inside this enclosed small space is measured. When all oxygen is consumed, it is recorded whether the candle is burning or not (case d). Different studies provided different data (Table 14, Table 15, Table 16).

Table 14. Oxygen and a bruning candle

\begin{tabular}{cc|c|c|l}
\hline & & \multicolumn{2}{c}{ Burning candle } & \multicolumn{1}{c}{ Total } \\
\cline { 3 - 4 } & & Yes $=+\mathbf{1}$ & \multicolumn{1}{c}{ No $=+\mathbf{0}$} & \\
\hline \multirow{2}{*}{ Oxygen } & Yes $=+1$ & 25 & 50 & 75 \\
\cline { 3 - 4 } & No $=+0$ & 0 & 25 & 25 \\
\hline Total & 25 & 75 & 100 \\
\hline
\end{tabular}

The data of Table 14 are analyzed by table 17 .

Table 15. Oxygen and a bruning candle

\begin{tabular}{|c|c|c|c|c|}
\hline & \multicolumn{2}{|c|}{ Burning candle } & \multirow[b]{2}{*}{ Total } \\
\hline & & Yes $=+1$ & $\mathrm{No}_{\mathrm{o}}=+\mathbf{0}$ & \\
\hline \multirow{3}{*}{ Oxygen } & Yes $=+1$ & 90 & 5 & 95 \\
\hline & No $=+0$ & 0 & 5 & 5 \\
\hline & Total & 90 & 10 & 100 \\
\hline
\end{tabular}

The data of Table 15 are analyzed by table 18 .

Table 16. Oxygen and a bruning candle

\begin{tabular}{cc|c|c|l}
\hline & & \multicolumn{3}{c}{ Burning candle } \\
\cline { 3 - 4 } & & \multicolumn{1}{c}{ Yes $=+\mathbf{1}$} & \multicolumn{1}{c}{ No $=+\mathbf{0}$} & Total \\
\hline \multirow{2}{*}{ Oxygen } & Yes $=+1$ & 25 & 50 & 75 \\
\cline { 3 - 4 } & No $=+0$ & 0 & 25 & 25 \\
\hline & Total & 25 & 75 & 100 \\
\hline
\end{tabular}

The data of Table 16 are analyzed by table 19 .

\section{Claim.}

The decision whether data are biased with respect to statistical analysis of conditions is supported by the index of unfairness.

\section{Proof.}

Different aspects of the relationship between oxygen and a burning candle are pictured by several studies. The data of Table 14 are analyzed by table 17. 
Table 17. The statistical analysis of the data of table 14 .



In our everyday life, the relationship between oxygen and a burning candle is clear: without oxygen no burning candle. In particular, oxygen itself is by far not the cause of a burning candle. However, the data of the study analyzed are to some extent self-contradictory. The study design is based on the assumption that $(a=25)=(d=25)$ and yielded an $\mathbf{p}(\mathbf{I O U})=\mathbf{0}$. As a consequence, it was possible to analyze the data for conditions (i. e. risk factors). We were able to recognize: without oxygen $n$ o burning candle $(\mathrm{p}(\mathrm{SINE})=1,000$; Chi Sq. 1 (SINE) $=0,000$; Chi Sq. $2(\mathrm{SINE})=0,000)$. However, the same study supports the hypothesis of a highly significant cause effect relationship between oxygen and a burning candle $(\mathrm{k}=+0,333$; P value $(\mathrm{k} \mid \mathrm{HGD})=0,000)$. Such a conclusion appears not to be justified. With respect to causal analysis it cannot be excluded that study is biased $(p(I O I)=0,5)$. Furthermore, neither the study analyzed nor another study has been able to provide reproduceable evidence of conditio per quam relationship $(\mathrm{p}(\mathrm{IMP})=0,500$; Chi Sq. $1(\mathrm{IMP})=33,333$; Chi Sq. 2(IMP) $=33,333$ ) between oxygen and a burning candle (i.e. if oxygen then burning candle). A higher p(IOI) appears not to justify the exclusion of data with respect to the analysis of conditions (i.e. risk factors). More fundamentally, it is important to take care about the index of independence (IOI) when data are considered for causal analysis. Even if the data support the hypothesis of a highly significant causal relationship, it is important to stress here that these data should not be used for that purposes. As next, the data of another study (Table 15) are analyzed by table 18 .

Table 18. The statistical analysis of the data of table 15 .

\begin{tabular}{|c|c|c|c|c|c|}
\hline \multirow{2}{*}{\multicolumn{2}{|c|}{$\mathbf{k}=+\mathbf{0}$}} & \multicolumn{2}{|c|}{$p(I O U)=0,850$} & \multicolumn{2}{|c|}{$p(I O I)=0,050$} \\
\hline & & & & & \\
\hline$P$ value $(k \mid$ HGD $)=$ & $\mathbf{0 , 0 0 0}$ & Chi Sq. $(\mathrm{k})=$ & 11,111 & & \\
\hline$p($ SINE $)=$ & 1,000 & Chi Sq. 1(SINE) = & 0,000 & Chi Sq. 2(SINE) = & $\mathbf{0 , 0 0 0}$ \\
\hline $\mathrm{p}(\mathrm{IMP})=$ & 0,950 & Chi Sq. 1(IMP) $=$ & 2,500 & Chi Sq. 2 (IMP) $=$ & 0,263 \\
\hline $\mathrm{p}\left(\mathrm{SINE}^{\wedge} \mathrm{IMP}\right)=$ & 0,950 & Chi Sq. $1\left(\right.$ SINE $\left.^{\wedge} \mathrm{IMP}\right)=$ & 2,500 & Chi Sq. $1\left(\mathrm{SINE}^{\wedge} \mathrm{IMP}\right)=$ & 0,263 \\
\hline $\mathrm{p}(\mathrm{EXCL})=$ & 0,100 & Chi Sq. $1(\mathrm{EXCL})=$ & 90,000 & Chi Sq. $2(\mathrm{EXCL})=$ & 85,263 \\
\hline
\end{tabular}

To be sure, we can state that the data (Table 15) support the hypotheses: without oxygen no burning candle (p(SINE) $=1,000$; Chi Sq. $1(\mathrm{SINE})=0,000$; Chi Sq. $2(\mathrm{SINE})=0,000)$ even if $\mathrm{p}(\mathrm{IOU})=0,85$. However, the problem with these data is that a significant causal relationship $(\mathrm{k}=+0,688$; $\mathrm{P}$ value $(\mathrm{k} \mid \mathrm{HGD})=0,000)$ is supported too, that a significant conditio per quam relationship $(\mathrm{p}(\mathrm{IMP})=0,950$; Chi Sq. 1(IMP) $=2,500$; Chi Sq. $2(\mathrm{IMP})=0,263$ ) is supported too and that a significant necessary and sufficient condition $\left(\mathrm{p}\left(\mathrm{SINE} \wedge \mathrm{IMP}^{\mathrm{I}}\right)=0,950\right.$; $\mathrm{Chi}$ Sq. 1 (SINE $\left.{ }^{\wedge} \mathrm{IMP}\right)=2,500$; Chi Sq. $\left.\left(\mathrm{SINE}^{\wedge} \mathrm{IMP}\right)=0,263\right)$ is supported too. In this case, the problem can be solved quickly. Oxygen is not the cause of a burning candle, even if $\mathrm{p}(\mathrm{IOI})$ is very low $(\mathrm{p}(\mathrm{IOI})=0,05)$. However, in most cases an investigator is faced with an unknown situation and needs reliable methods which are of help to decide whether the data analyzed are worth being analyzed or not. In toto, it is not enough to rely only on statistical measures. The quality of data fundamentally determined by study design and other factors must be considered too. The statistical analysis (Table 18) of the data of table 15 is of only limited value. We just cannot decide what is true and what is not true. A high $\mathrm{p}(\mathrm{IOU})$ can be associated with bias and the data should be analyzed only with very great care or not at all even if $\mathrm{p}(\mathrm{IOI})$ is small.

\section{Quod erat demonstrandum.}

\section{Discussion}

Kicinski et al. (Kicinski et al., 2015) and other (Lin, 2018; Lin \& Chu, 2018) investigated publication bias in metaanalyses and were able to find evidence of publication bias in systematic reviews. The application of appropriate statistical methods in biomedical research alone on data collected from clinical trials and other studies is not enough and does not guarantee conclusions which are valid and reproduceable. The use of funnel plot's (Light \& 
Pillemer, 1984) is one way to detect publication bias in an examination. Other formal tests for publication bias were developed by Begg and Mazumdar (Begg \& Mazumdar, 1994) and by Egger et al . (Egger, Smith, Schneider, \& Minder, 1997). Higgins et al. (Higgins \& Thompson, 2002) developed a statistical tool to measure the extent of heterogeneity in a meta-analysis. In a slightly different way, the development and the use of other effective measures to reduce publication bias in clinical trials and other studies is necessary and justified. The analysis of data for causal relationships is not without problems but not impossible. However, bias in this context may invalidate the conclusions drawn. Again, there are justified reasons to doubt whether data as such and undifferentiated are suitable for a systematic review and meta-analyses. According to this account, one has to examine and to consider the different kinds of bias and as a rule of thumb, for causal analysis, a study design should assure as much as possible that at least

$$
p(I O U)+p(I O U)<0,5
$$

The following table (Table 19) may provide a useful overview on this relationship.

Table 19. The relationship between $\mathrm{p}(\mathrm{IOU})$ and $\mathrm{p}(\mathrm{IOI})$. Soft rule.

\begin{tabular}{|c|c|c|c|c|}
\hline & & p(IOI) & & \\
\hline & & $<0,5$ & $\geq 0,5$ & Total \\
\hline $\mathrm{n}(\mathrm{IOU})$ & $<0,5$ & Causal analysis may be possible. & Analysis of conditions. & \\
\hline p(1) & $\geq 0,5$ & Analysis of conditions, with great care! & No analysis. Data are potentially biased. & \\
\hline & Total & & & 1 \\
\hline
\end{tabular}

In its various forms and shapes, the concept of causality plays a fundamental role in the history of human science. However, and perhaps for this reason especially the relationship between causality and statistics (Dempster, 1990; Korch, 1965) is governed by too many prevailing prejudices. Such prejudices are stemming from different sources one of which is study design. In particular to avoid confusion and in order to prevent an unjustified backward and discredited view on the new statistical methods available to analyze causal relationships from data, studies which are aimed to analyze data for causal relationships should assure as much as possible

$$
p(I O U)+p(I O U)<0,25
$$

until better methods are known and available to deal with bias due to study design. The table 20 may provide a useful overview.

Table 20. The relationship between $\mathrm{p}(\mathrm{IOU})$ and $\mathrm{p}(\mathrm{IOI})$ and causal analysis. Hard rule.

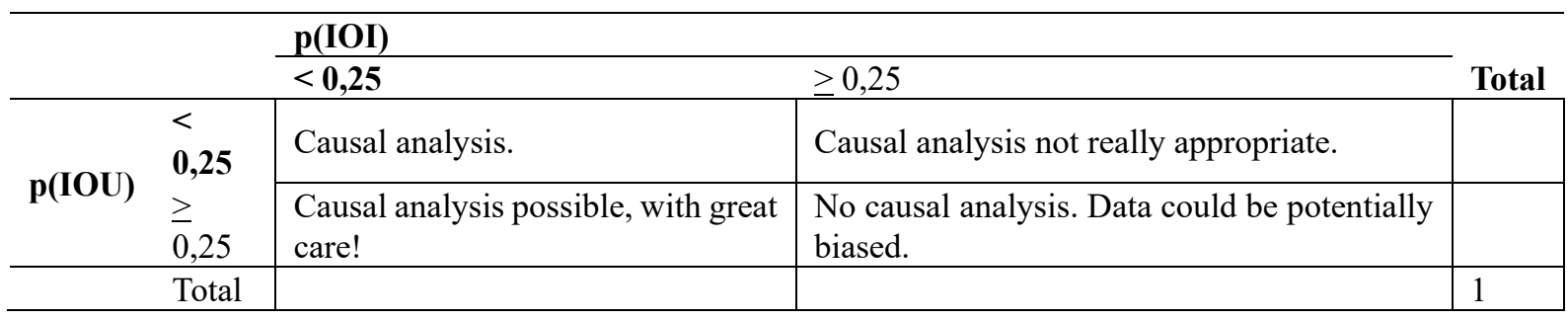

A very low $\mathrm{p}(\mathrm{IOI})$ is not necessary to recognize conditions. However, a very high $\mathrm{p}(\mathrm{IOI})$ can indicate extremely biased data and the conclusions drawn could be potentially invalid. Even if $p(I O U)$ is very low, data with a $p(I O I)$ beyond 0,75 are of very limited value even for the for the analysis of conditions.

\section{Conclusion}

Historically, much effort has been put into the rapid development of inferential methods such as estimation and hypothesis testing et cetera while study design aspects have not been formally considered to a necessary extent. However, the best inferential methods will face their natural limits when confronted with biased data. The study design has a crucial impact on the quality of data in clinical studies and trials. The new non inferential methods, the index of unfairness (IOU) and the index of independence (IOI), are of use to reduce bias due to data gained by 
an inappropriate study design. Even ex post, the robustness of these non-inferential methods will convince the researcher.

\section{Financial support and sponsorship}

Nil.

\section{Conflict of interest statement}

The authors declare that no conflict of interest exists according to the guidelines of the International Committee of Medical Journal Editors.

\section{References}

Altman, D. G. (1999). Practical statistics for medical research. Boca Raton, Fla: Chapman \& Hall/CRC.

Arbuthnott, J. (1710). An Argument for Divine Providence, Taken from the Constant Regularity Observ'd in the Births of Both Sexes. By Dr. John Arbuthnott, Physitian in Ordinary to Her Majesty, and Fellow of the College of Physitians and the Royal Society. Philosophical Transactions of the Royal Society of London, 27(325-336), 186-190. https://doi.org/10.1098/rstl.1710.0011

Baker, M. (2016). 1,500 scientists lift the lid on reproducibility. Nature, 533(7604), 452-454. https://doi.org/10.1038/533452a

Barukčić I. (2019). Smoking of tobacco is the cause of human lung cancer. Journal of Drug Delivery and Therapeutics, 9(1-s), 148-160. https://doi.org/10.22270/jddt.v9i1-s.2273

Barukčić, I. (1989). Die Kausalität (1. Aufl.). Hamburg: Wiss.-Verl.

Barukčić, I. (1997). Die Kausalität (2., völlig überarb. Aufl.). Wilhelmshaven: Scientia.

Barukčić, I. (2005). Causality: New statistical methods. Norderstedt, Germany: Books on Demand GmbH.

Barukčić, I. (2006a). Causality: New statistical methods (2. Aufl.). Norderstedt: Books on Demand.

Barukčić, I. (2006b). New Method for Calculating Causal Relationships. Retrieved from http://www.medicine.mcgill.ca/epidemiology/hanley/ibc2006program.pdf

Barukčić, I. (2009a). Causality I. A theory of energy, time and space (5. ed., 14. rev).

Barukčić, I. (2009b). Causality II. A theory of energy, time and space (5. ed., 13. rev).

Barukčić, I. (2011a). Anti Heisenberg-Refutation Of Heisenberg's Uncertainty Relation: In: ADVANCES IN QUANTUM THEORY: Proceedings of the International Conference on Advances in Quantum Theory, Växjö, (Sweden), 14-17 June 2010. In American Institute of Physics - Conference Proceedings (Vol. 1327, pp. 322325). https://doi.org/10.1063/1.3567453

Barukčić, I. (2011b). The Equivalence of Time and Gravitational Field. Physics Procedia, 22, 56-62. https://doi.org/10.1016/j.phpro.2011.11.008

Barukčić, I. (2012). Anti-Bell - Refutation of Bell's theorem: In: Quantum Theory: Reconsideration of Foundations-6 (QTRF6), Växjö, (Sweden), 11-14 June 2012. In American Institute of Physics - Conference Proceedings (Vol. 1508, pp. 354-358). https://doi.org/10.1063/1.4773147

Barukčić, I. (2016a). The Mathematical Formula of the Causal Relationship k. International Journal of Applied Physics and Mathematics, 6(2), 45-65. https://doi.org/10.17706/ijapm.2016.6.2.45-65

Barukčić, I. (2016b). The Physical Meaning of the Wave Function. Journal of Applied Mathematics and Physics, 4(6), 988-1023. https://doi.org/10.4236/jamp.2016.46106

Barukčić, I. (2016c). Unified Field Theory. Journal of Applied Mathematics and Physics, 4(8), 1379-1438. https://doi.org/10.4236/jamp.2016.48147

Barukčić, I. (2017a). Helicobacter pylori-The Cause of Human Gastric Cancer. Journal of Biosciences and Medicines, 5(2), 1-9. https://doi.org/10.4236/jbm.2017.52001

Barukčić, I. (2017b). Theoriae causalitatis principia mathematica. Norderstedt: Books on Demand.

Barukčić, I. (2018a). Epstein Bar Virus-The Cause of Hodgkin's Lymphoma. Journal of Biosciences and Medicines, 6(1), 75-100. https://doi.org/10.4236/jbm.2018.61008

Barukčić, I. (2018b). Fusobacterium nucleatum-The Cause of Human Colorectal Cancer. Journal of Biosciences and Medicines, 6(3), 31-69. https://doi.org/10.4236/jbm.2018.63004 
Barukčić, I. (2018c). Gastric Cancer and Epstein-Barr Virus Infection. Modern Health Science, 1(2), 1-18. https://doi.org/10.30560/mhs.v1n2p1

Barukčić, I. (2018d). Helicobacter Pylori is the Cause of Gastric Cancer. Modern Health Science, 1(1), 43-50. https://doi.org/10.30560/mhs.v1n1p43

Barukčić, I. (2018e). Human Cytomegalovirus is the Cause of Glioblastoma Multiforme. Modern Health Science, 1(2), 19. https://doi.org/10.30560/mhs.v1n2p19

Barukčić, I. (2018f). Human Papillomavirus-The Cause of Human Cervical Cancer. Journal of Biosciences and Medicines, 6(4), 106-125. https://doi.org/10.4236/jbm.2018.64009

Barukčić, I. (2018g). Mycobacterium Avium Subspecies Paratuberculosis: The Cause Of Crohn's Disease. Modern Health Science, 1(1), 19-34. https://doi.org/10.30560/mhs.v1n1p19

Barukčić, I. (2018h). Epstein-Barr virus is the cause of multiple sclerosis. International Journal of Current Medical and Pharmaceutical Research, 4(9(A)), 3674-3682. http://dx.doi.org/10.24327/23956429.ijcmpr20180538

Barukčić, K., Barukčić, J. P., \& Barukčić, I. (2018). Epstein-Barr virus is the cause of rheumatoid arthritis. Romanian Journal of Rheumatology, 27(4), 148-163.

Bernoulli, J. (1713). Ars conjectandi, Opus posthumus: Accedit Tractatus de seriebus infinitis; et epistola Gallice scripta De Ludo Pilae Reticularis. Basileae (Basel, Suisse): Impensis Thurnisiorum [Tournes], fratrum. https://doi.org/10.3931/e-rara-9001

Bienaymé, I.-J. (1846). Sur les probabilités des erreurs d'après la méthode des moindres carrés. Journal De Mathématiques Pures Et Appliquées, 1(17), 33-78.

Bortkiewicz, L. (Ed.). (1898). Das Gesetz der kleinen Zahlen: [Transl. into English: The law of small numbers]. Leipzig (Germany): $\quad$ B.G. $\quad$ Teubner. $\quad$ Retrieved from https://ia802308.us.archive.org/33/items/dasgesetzderklei00bortrich/dasgesetzderklei00bortrich.pdf

Charan, J.,\& Biswas, T. (2013). How to calculate sample size for different study designs in medical research? Indian Journal of Psychological Medicine, 35(121). https://doi.org/10.4103/0253-7176.116232

Conover, W. J. (1974). Some Reasons for Not Using the Yates Continuity Correction on $2 \times 2$ Contingency Tables. Journal of the American Statistical Association, 69(346), 374-376. https://doi.org/10.1080/01621459.1974.10482957

Cornfield, J. (1951). A method of estimating comparative rates from clinical data; applications to cancer of the lung, breast, and cervix. Journal of the National Cancer Institute, 11(6), 1269-1275.

DeGroot, M. H., Schervish, M. J., Fang, X., Lu, L., \& Li, D. (2005). Probability and Statistics (Third Edition [Rep. $\&$ arr. ed.]). Beijing (China): Higher Education Press.

Dorey, F. (2010). In Brief: The P Value: What Is It and What Does It Tell You? Clinical Orthopaedics and Related Research, 468(8), 2297-2298. https://doi.org/10.1007/s11999-010-1402-9

Edwards, A. W. F. (1963). The Measure of Association in a $2 \times 2$ Table. Journal of the Royal Statistical Society. Series A (General), 126(1), 109. https://doi.org/10.2307/2982448

Egger, M., Smith, G. D., Schneider, M., \& Minder, C. (1997). Bias in meta-analysis detected by a simple, graphical test. $B M J, 315(7109), 629-634$. https://doi.org/10.1136/bmj.315.7109.629

Fisher, R. A. (1922). On the Interpretation of $\chi 2$ from Contingency Tables, and the Calculation of P. Journal of the Royal Statistical Society, 85(1), 87. https://doi.org/10.2307/2340521

Fisher, R. A. (1935). The Logic of Inductive Inference. Journal of the Royal Statistical Society, 98(1), 39. https://doi.org/10.2307/2342435

Fisher, Ronald A. (1925). Statistical Methods for Research Workers. Edinburgh: Oliver and Boyd. Retrieved from http://www.haghish.com/resources/materials/Statistical_Methods_for_Research_Workers.pdf

Gomes, G. (2009). Are Necessary and Sufficient Conditions Converse Relations. Australasian Journal of Philosophy, 87, 375-387. https://doi.org/10.1080/00048400802587325

Gonin, H. T. (1936). XIV. The use of factorial moments in the treatment of the hypergeometric distribution and in tests for regression. The London, Edinburgh, and Dublin Philosophical Magazine and Journal of Science, 21(139), 215-226. https://doi.org/10.1080/14786443608561573

Grimes, D. A., \& Schulz, K. F. (2002). Bias and causal associations in observational research. Lancet (London, 
England), 359(9302), 248-252. https://doi.org/10.1016/S0140-6736(02)07451-2

Grizzle, J. E. (1967). Continuity Correction in the $\chi 2$-Test for $2 \times 2$ Tables. The American Statistician, 21(4), 28. https://doi.org/10.2307/2682103

Hanley, J. A. (1983). If Nothing Goes Wrong, Is Everything All Right? JAMA, 249(13), 1743.

Hogg, R. V., \& Craig, A. T. (2004). Introduction to Mathematical Statistics. Beijing: Higher Education Press.

Hopewell, S., Loudon, K., Clarke, M. J., Oxman, A. D., \& Dickersin, K. (2009a). Publication bias in clinical trials due to statistical significance or direction of trial results. Cochrane Database of Systematic Reviews, (1). https://doi.org/10.1002/14651858.MR000006.pub3

Hume, D. (1739). David Hume: A Treatise of Human Nature (Second Edition). Oxford University Press. https://doi.org/10.1093/actrade/9780198245872.book.1

Hunter, J. P., Saratzis, A., Sutton, A. J., Boucher, R. H., Sayers, R. D., \& Bown, M. J. (2014). In meta-analyses of proportion studies, funnel plots were found to be an inaccurate method of assessing publication bias. Journal of Clinical Epidemiology, 67(8), 897-903. https://doi.org/10.1016/j.jclinepi.2014.03.003

Huygens, C. (1629-1695), \& van Schooten, F. (1615-1660). (1657). De ratiociniis in ludo alae: In: Exercitationum mathematicarum liber primus [- quintus]. Lugdunum Batavorum (Leiden, The Netherlands): ex officina Johannis Elsevirii. https://doi.org/10.3931/e-rara-8813

Isserlis, L. (1918). On the Value of a Mean as Calculated from a Sample. Journal of the Royal Statistical Society, 81(1), 75. https://doi.org/10.2307/2340569

Joober, R., Schmitz, N., Annable, L., \& Boksa, P. (2012). Publication bias: What are the challenges and can they be overcome? Journal of Psychiatry \& Neuroscience, 37(3), 149-152. https://doi.org/10.1503/jpn.120065

Jovanovic, B. D., \& Levy, P. S. (1997). A Look at the Rule of Three. The American Statistician, 51(2), 137-139.

Kaplan, R. M., Chambers, D. A., \& Glasgow, R. E. (2014). Big Data and Large Sample Size: A Cautionary Note on the Potential for Bias. Clinical and Translational Science, 7(4), 342-346. https://doi.org/10.1111/cts.12178

Kleijnen, J., \& Knipschild, P. (1992). Review articles and publication bias. Arzneimittelforschung, 45(2), 587-591.

Kolmogoroff, A. (1933). Grundbegriffe der Wahrscheinlichkeitsrechnung. Berlin, Heidelberg: Springer Berlin Heidelberg. https://doi.org/10.1007/978-3-642-49888-6

LaPlace, Pierre Simon de. (1812). Théorie analytique des probabilités. Paris (France): Courcier. https://doi.org/10.3931/e-rara-9457

Lau, J., Ioannidis, J. P. A., Terrin, N., Schmid, C. H., \& Olkin, I. (2006). The case of the misleading funnel plot. BMJ, 333(7568), 597-600. https://doi.org/10.1136/bmj.333.7568.597

Light, R. J., \& Pillemer, D. B. (1984). Summing up. The science of reviewing research. Cambridge, Mass., USA: Harvard University Press.

Louis, T. A. (1981). Confidence Intervals for a Binomial Parameter after Observing No Successes. The American Statistician, 35(3), 154-154.

Lyapunov, A. M. (1901). Nouvelle forme du théorème sur la limite de probabilité. Mémoires de l'Académie Impériale Des Sciences de St.-Pétersbourg. Série VIIIe. Classe Physico-Mathématique, 12, 1-24.

Moher, D., Dulberg, C. S., \& Wells, G. A. (1994). Statistical Power, Sample Size, and Their Reporting in Randomized Controlled Trials. JAMA: The Journal of the American Medical Association, 272(2), 122. https://doi.org/10.1001/jama.1994.03520020048013

Moivre, A. (1733). Approximatio ad summam terminorum binomii $(a+b) n$ in seriem expansi. London: Privately (Publisher not identified). Retrieved from https://www.york.ac.uk/depts/maths/histstat/demoivre.pdf

Moivre, A. de [1667-1754]. (1718). The Doctrine of Chances or a Method of Calculating the Probability of Events in Play. London: printed by W. Pearson for the author. https://doi.org/10.3931/e-rara-10420

Mosteller, F. (1968). Association and Estimation in Contingency Tables. Journal of the American Statistical Association, 63(321), 1. https://doi.org/10.2307/2283825

Murad, M. H., Chu, H., Lin, L., \& Wang, Z. (2018). The effect of publication bias magnitude and direction on the certainty in evidence. BMJ Evidence-Based Medicine, 23(3), 84-86. https://doi.org/10.1136/bmjebm-2018110891 
Noordzij, M., Dekker, F. W., Zoccali, C., \& Jager, K. J. (2010). Measures of Disease Frequency: Prevalence and Incidence. Nephron Clinical Practice, 115, c17-c20. https://doi.org10.1159/000286345

Pagano, M., \& Gauvreau, K. (2018). Principles of Biostatistics (2nd ed.). Milton: CRC Press. Retrieved from https://ebookcentral.proquest.com/lib/gbv/detail.action?docID=5301930

Panagiotakos, D. B. (2008). The Value of p-Value in Biomedical Research. The Open Cardiovascular Medicine Journal, 2, 97-99. https://doi.org/10.2174/1874192400802010097

Pearson, K. (1900). X. On the criterion that a given system of deviations from the probable in the case of a correlated system of variables is such that it can be reasonably supposed to have arisen from random sampling. The London, Edinburgh, and Dublin Philosophical Magazine and Journal of Science, 50(302), 157-175. https://doi.org/10.1080/14786440009463897

Pearson, K., \& Heron, D. (1913). On Theories of Association. Biometrika, 9(1-2), 159-315. https://doi.org/10.1093/biomet/9.1-2.159

Pearson, Karl. (1899). XV. On certain properties of the hypergeometrical series, and on the fitting of such series to observation polygons in the theory of chance. The London, Edinburgh, and Dublin Philosophical Magazine and Journal of Science, 47(285), 236-246. https://doi.org/10.1080/14786449908621253

Poisson, S. D. (1837). Recherches sur la Probabilité des jugements en matière criminelle et en matière civile, précédées des règles générales du calcul des probabilitiés. Paris, France: Bachelier. Retrieved from https://www-liphy.ujf-grenoble.fr/pagesperso/bahram/Phys_Stat/Biblio/Poisson_Proba_1838.pdf

Pólya, G. (1920). Über den zentralen Grenzwertsatz der Wahrscheinlichkeitsrechnung und das Momentenproblem: [In English: On the central limit theorem of probability calculation and the problem of moments]. Mathematische Zeitschrift, 8(3-4), 171-181. https://doi.org/10.1007/BF01206525

Quine, M. P., \& Robinson, J. (1985). Efficiencies of Chi-Square and Likelihood Ratio Goodness-of-Fit Tests. The Annals of Statistics, 13(2), 727-742. https://doi.org/10.1214/aos/1176349550

Rahme, E., \& Joseph, L. (1998). Exact sample size determination for binomial experiments. Journal of Statistical Planning and Inference, 66, 83-93. https://doi.org/10.1016/S0378-3758(97)00068-2

Retrieved from http://www.archive.org/stream/oeuvresphilosoph00leibuoft\#page/n9/mode/2up

Rumke, C. L. (1975). Implications of the Statement: No Side Effects Were Observed. The New England Journal of Medicine, 292(7), 372-373. https://doi.org/10.1056/NEJM197502132920723

Sachs, L. (1992). Angewandte Statistik. Berlin, Heidelberg: Springer Berlin Heidelberg.

Scheid, H. (1992). Wahrscheinlichkeitsrechnung (Vol. 6). Mannheim: BI-Wiss.-Verl.

Schervish, M. J. (1996). P Values: What They are and What They are Not. The American Statistician, 50(3), 203206. https://doi.org/10.1080/00031305.1996.10474380

Szumilas, M. (2010). Explaining Odds Ratios. J Can Acad Child Adolesc Psychiatry, 19, 227-229.

Tchébychef, P. L. (1867). Des valeurs moyennes. Journal de Mathématiques Pures et Appliquées, 2(12), 177-184.

von Leibniz, G. W. F. (1765). Oeuvres philosophiques latines \& francoises de feu Mr. de Leibniz. Amsterdam (NL): Chez Jean Schreuder.

Warrens, M. J. (2008). On Association Coefficients for $2 \times 2$ Tables and Properties That Do Not Depend on the Marginal Distributions. Psychometrika, 73(4), 777-789. https://doi.org/10.1007/s11336-008-9070-3

Wertheimer, R. (1968). Conditions. Journal of Philosophy, 65, 355-364.

Yates, F. (1934). Contingency Tables Involving Small Numbers and the $\chi 2$ Test. The Journal of the Royal Statistical Society (Supplement), 1(2), 217-235. https://doi.org/10.2307/2983604

Yule, G. U. (1900). On the Association of Attributes in Statistics: With Illustrations from the Material of the Childhood Society, \&c. Philosophical Transactions of the Royal Society A Mathematical, Physical and Engineering Sciences, 194(252-261), 257-319. https://doi.org/10.1098/rsta.1900.0019

Zwetsloot, P. P., Van Der Naald, M., Sena, E. S., Howells, D. W., IntHout, J., De Groot, J. A., ... Wever, K. E. (2017). Standardized mean differences cause funnel plot distortion in publication bias assessments. ELife, 6 . https://doi.org/10.7554/eLife.24260 


\section{Copyrights}

Copyright for this article is retained by the author(s), with first publication rights granted to the journal.

This is an open-access article distributed under the terms and conditions of the Creative Commons Attribution license (http://creativecommons.org/licenses/by/4.0/). 